\title{
PREVALENCE OF BORDERLINE PERSONALITY DISORDER AND ITS ASSOCIATION WITH DEMOGRAPHIC FACTORS AMONG UNIVERSITY STUDENTS OF PAKISTAN
}

\author{
a,bHafsa Hayee*. aTahira Raana, bImran I. Haider \\ ${ }^{a}$ Department of Human Development \& Family Studies, University of Home Economics. Lahore, Pakistan. \\ ${ }^{b}$ Department of Behavioral and Health Sciences, Fatima Memorial Hospital, Lahore, Pakistan.
}

ARTICLE INFO

\section{Article History}

Received: January 18, 2020

Revised: March 12, 2020

Accepted: April 27, 2020

\section{Keywords}

Borderline Personality

Disorder

Young

Adults

Demographic factors
A B S T R A C T

Borderline Personality Disorder (BPD) is a psychological disorder, which could cause severe problems in self-functioning, emotion regulation, and interpersonal relationships. This study aimed to assess BPD among university students and evaluating the association of BPD with demographic factors among the students. Three private sector universities were selected from Lahore. A cross-sectional survey was conducted by using questionnaire composed of demographic factors (gender, age and university) and Borderline Personality Inventory (BPI- cut 20). An estimated data of 700 undergraduates was collected through stratified sampling technique. The collected data was analyzed through SPSS (Version 17). There were $(46 \%)$ males and (54\%) female participants, whose mean age was $21 \pm 1.81$ years, at the time of data collection. The findings indicated, BPD $(\geq 10)$ in majority $(62 \%)$ of the participants. BPD was more prevalent among the age group of 18-21 years. Application of the Chi-square test confirmed non-significant association $(p<0.05)$ between age, and gender, with BPD. The strength of the relationship was assessed through the odds ratio (OR). Association between gender and $\mathrm{BPD}(\mathrm{OR}=1.026, \mathrm{CI}=$ $0.755-1.392)$ and age and $\mathrm{BPD}(\mathrm{OR}=0.880, \mathrm{CI}=0.637-1.216)$, university and $\mathrm{BPD}$ $(\mathrm{OR}=0.531, \mathrm{CI}=0.381-0.742)$ reported a statistically significant association with BPD $(\mathrm{p}<0.001)$. Further the Logistic regression affirmed, impact of rank, of the educational institution (university) had significant effect on prevalence of BPD. Therefore, it is concluded that students (young adults) are more at risk of being affected by BPD, who are studying in the universities with higher socio-economic status. So, it can be supposed that environment (rank, location and circumstances) of the university is one of the dominating factors playing a significant role in the prevalence of BPD among young adults.

Corresponding Author: Hafsa Hayee

Email: hafsa.hayee@gmail.com

(C) The Author(s) 2021.

\section{INTRODUCTION}

Borderline personality disorder (BPD) is a psychological disorder associated with functional damage and a high suicidal rate. Therefore, it is linked with other Psychiatric and Personality Disorders (Kaess et al., 2014), The term borderline, in the field of mental health, refers to the disorder, that is on border with a psychotic and neurotic mental disorder (Paris, 2018). Though the exact cause of BPD is not known, it is assumed that genetical and environmental factors play a vital role in identifying BPD (Leichsenring et al., 2011; Taravati and Kaklar, 2013). BPD is considered usually prevalent 
among young adults with prolonged psychological symptoms (Chanen, 2015; Gunderson et al., 2018), It is suspected that major symptoms of BPD can be identified at late adolescent or early adulthood. The empirical study suggests that the most stressed, anxious, and depressed young adults, studying in high-class universities are more at risk (Beiter et al., 2015; Shaikh et al., 2017).

Recent studies proposes that BPD can be found in normal population of college and university students (Francey et al., 2017; Meaney et al., 2016a). Further, prevalence of BPD is associated with poor educational levels and a high risk of declined study among the population of young adults studying in universities (Tomko et al., 2014). Literature also suggests that if BPD is not diagnosed at its initial stage, it can lead to a serious psychological issue, adversely affecting an individual's emotional functioning in all aspects of life. Similarly, research evidence further suggests that BPD is suspected to be more prevalent in the population of young adults. Therefore, researcher of the current study has aimed to determine the prevalence of BPD among the population of students who are young adults and studying in the universities in Pakistan.

Age is an important factor that had been widely studied with Personality Disorders. A cultural study has provided evidence that most serious mental health issues begin before the age of 25 years (Jones, 2013). Most of the young individuals by the age of twenty-one years are suspected to be diagnosed with one or more psychiatric disorders (Chanen, 2015). Early signs of BPD can be observed in the early 20s, and young adulthood (Sharp and Fonagy, 2015; Moran et al., 2016). Studies also suggests that symptoms of BPD can be witnessed during the time of adolescence as well (Newton-Howes, Clark, et al., 2015; Sharp and Fonagy, 2015). However, recent researches suggests that personality characteristics of BPD are not evident till adulthood, and if not diagnosed and treated on time, can severely abrupt the life patterns of a person (Gunderson et al., 2018; Thornton, 2018).

Another important factor that has been widely studied with BPD is gender. Differences have been observed in characteristics of BPD among males and females. In many studies, important variances in the level and prevalence of BPD among males and females have been noticed. In the late 1980s, BPD was more common in females. Therefore, it was considered female's disorder.
In early 2000s, opposing consequences were obtained. In the later research no differences were found in factors of BPD among males and females (Zlotnick et al., 2002; Johnson et al., 2003; Kaess et al., 2014). However, more recent studies suggest difference between genders and prevalence of BPD (Benson et al., 2017; Zanarini et al., 2011).

According to the latest research evidence, BPD has clear features of personality disorder at a young age, highlighting the association between the severity of personality disorder and adulthood (Sharp and Fonagy, 2015; Fonseca-Pedrero et al., 2011; Moran et al., 2016). Further, the research evidence emphasized age as an important characteristic to study the occurrence of BPD. BPD is assumed to be more common among young adults. Therefore, this study is aimed to assess prevalence of BPD and its association with demographic factors. Further it assessed either there is association between age, gender and universities (as an educational institution) with BPD or not.

\section{METHODOLOY}

This section describes the materials used to conduct the study and methods that are undertaken.

\section{Research Design}

This is quantitative research. A descriptive crosssectional survey is used to conduct this study. Data is collected through a structured questionnaire composed of demographic factors and standardized psychological tool, Borderline Personality Inventory (BPI- cut 20). BPI cut 20 is a highly reliable tool developed by (Leichsenring et al., 2011) and it consists of close-ended questions with a dichotomous scale (Yes/No). Those who scored ten or above $(\geq 10)$ are diagnosed with BPD, and vice versa.

Approval of the research was granted by the Institutional Review Board (IRB). Further written permission from authorities of the selected universities was taken to conduct the study. Students were verbally informed about the aim of this research and their written consent was taken, before they participated in the survey. For data sampling three private sector universities, all based in Lahore, Pakistan was selected. The list of recognized private Universities by the Higher Education Commission (HEC) was obtained. Further the list if universities was formulated according to their ranking in HEC. The three universities were randomly 
selected from it (the inclusive criteria of selecting the university were: they should be located in the mid of the city Lahore and easily accessible by majority of the population). The representative sample of students (undergraduates) from the most populated departments of these universities were selected through a stratified sampling procedure. Participants were between ages 18 to 25 years. They were unmarried and in good physical health.

A questionnaire composed of demographic questions and BPD scale was given to students, and they were given a time of 10-20 minutes to complete. An estimated sample of seven hundred students was collected. All the forms with missing data or incomplete information were excluded. Considering confidentiality, Roman numeral codes were assigned to universities, i.e., University I, University II, and University III. Data was analyzed through SPSS 21.0 software. The prevalence of BPD in different age groups, gender, and universities was assessed through frequency distribution after computing the BPD score and its categorization into BPD and nonBPD adults. Further, the relationship between BPD and age, gender, and the university was assessed through the chi-square test of association, independent sample t-test, odds ratio analysis, and logistic regression was applied between BPD and educational institutions that were taken as variables.

\section{RESULTS}

The study was carried out on young adults, studying in private universities of Lahore. All of the students were single and of age between 18-25 years, and were undergraduates. Descriptive statistics were applied; percentage, frequency, mean, and standard deviation were calculated. The mean age of the male and female participants was 21 years $(S D=1.92,1.66)$. The BPD prevalence in the overall sample $(\mathrm{n}=700)$ was $62 \%$. The relationship between demographic factors (gender, age, and university) and BPD status was assessed through a chi-square test of association independent sample t-test, odds ratio analysis, and logistic regression.

Table 1 shows that there were slightly more female participants (54\%) than male (46\%), ages $18-21$ years, at the time of data collection. The $t$ test was applied to assess the association, the significant results $(\mathrm{P}<0.05)$ obtained between BPD and Universities, suggesting that prevalence of BPD among the students varies according to their universities.

Table 1. Prevalence of BPD and demographic factors.

\begin{tabular}{lccccc}
\hline Predictors & \multicolumn{5}{c}{ Borderline Personality Disorder (BPD) } \\
\cline { 2 - 6 } & $n(\%)$ & $\mathrm{M}$ & $\mathrm{SD}$ & $t / / \mathrm{F}$ & $p$-value \\
\hline Gender & & & & \\
\hline Male & $325(46)$ & 10.35 & 3.689 & 0.415 & .678 \\
Female & $375(54)$ & 10.24 & 3.322 & & \\
\hline Age & & & & & .943 \\
\hline $18-21$ & $433(62)$ & 10.30 & 3.316 & .071 & \\
University & $267(48)$ & 10.28 & 3.776 & & \\
\hline I & & & & & \\
II & $250(35)$ & 10.14 & 3.270 & \multirow{2}{*}{3.001} \\
III & $250(35)$ & 11.20 & 3.335 & & \\
\hline
\end{tabular}

Note: $\mathrm{N}=700, t=$ Independent sample $\mathrm{t}$-test, $\mathrm{F}=$ Chi-square test of association, $\mathrm{p}$-value $=$ Significant value.

University I, II, III are codes given to the universities to keep the identity confidential.

Table 2. Association between Borderline Personality Disorder and demographic factors.

\begin{tabular}{lcccccc}
\hline Factors & Non-BPD & BPD & Chi-square & p-value & Odds Ratio & $95 \%$ CI \\
\hline Gender & & & & & & \\
\hline Male & 125 & 200 & 0.026 & 0.540 & 1.026 & $0.755-1.392$ \\
Female & 142 & 233 & & & & \\
\hline Age & 143 & 246 & 0.597 & 0.43 & 0.880 & $0.637-1.216$ \\
\hline 18-21 years & 103 & 156 & & & & \\
22-25 years & &
\end{tabular}




\begin{tabular}{|c|c|c|c|c|c|c|}
\hline \multicolumn{7}{|l|}{ Universities } \\
\hline \multicolumn{7}{|l|}{ University 1} \\
\hline Others & 166 & 284 & 0.840 & 0.32 & 0.862 & $0.628-1.184$ \\
\hline University-I & 101 & 149 & & & & \\
\hline \multicolumn{7}{|l|}{ University II } \\
\hline Others & 199 & 251 & 19.73 & 0.000 & 2.122 & $1.518-2.90$ \\
\hline University-II & 68 & 182 & & & & \\
\hline \multicolumn{7}{|l|}{ University III } \\
\hline Others & 169 & 331 & 13.98 & 0.000 & 0.531 & $0.381-0.742$ \\
\hline University-III & 98 & 102 & & & & \\
\hline \multicolumn{7}{|c|}{ University I vs. II } \\
\hline University-I & 101 & 149 & 9.734 & 0.000 & 1.814 & $1.246-2.64$ \\
\hline University-II & 68 & 182 & & & & \\
\hline \multicolumn{7}{|c|}{ University I vs. III } \\
\hline University-I & 101 & 149 & 3.72 & 0.657 & 0.705 & $0.484-1.02$ \\
\hline University-III & 98 & 102 & & & & \\
\hline \multicolumn{7}{|c|}{ University II vs. III } \\
\hline University-II & 68 & 182 & 22.68 & 0.000 & 0.389 & $0.262-0.576$ \\
\hline University-III & 98 & 102 & & & & \\
\hline \multicolumn{7}{|c|}{$\begin{array}{l}\text { Note: Borderline Personality Inventory (BPI-cut } 20 \text { ) was used to assess BPD. BPI cut } 20 \text { is a short form of BPI. It is } \\
\text { categorized into two categories to diagnose BPD. Non-BPD is referred to the category which scored }<10 \text { and is } \\
\text { considered 'normal'. While there is another category named BPD, which is referred to as the category which scored } \\
\geq 10 \text { and is considered with the existence of BPD. } \\
\text { The variable 'University' is further coded I, II, and III to keep their identity confidential. }\end{array}$} \\
\hline
\end{tabular}

According to the data given in Table 2, the university showed a strong association with BPD. Gender and age had a statistically non-significant association with BPD $(\mathrm{p}<0.05)$. The BPD was equally prevalent in males and female adults. Therefore, odds ratio analysis shows that gender was not a risk factor for the prevalence of BPD. The point odds ratio shows that females had 1.02 times more risk to get BPD as compared to males but a $95 \%$ confidence interval (CI) included the value 1 which showed non-significant evidence for the higher prevalence of BPD in females. Similarly, age did not show a significant difference in prevalence in different age groups that led to non-significant association (OR = 0.880, 95\% CI: 0.637-1.216) between age groups and BPD. The chi-square test of association produced nonsignificant results $(\mathrm{p}>0.001)$ and odds ratio. However, the risk of BPD was more among the students of university II. On the other side, university III had a significantly low risk of BPD ( $p<0.001)$ as compared to other universities as its odds ratio had a value less than 1. Therefore, results suggested that ranking (hierarchical position) of the university had a significant $(p<0.05)$ association with the prevalence of BPD among university students. Logistic regression model presented in Table 3, the highly significant $(\mathrm{p}<0.05)$ results, showing that University students studying in higher rank university shown more cases of BPD comparative to the other two. Diversity in the results obtained from the university has been observed in the prevalence of BPD among three universities.

\section{DISCUSSION}

This study aimed to assess prevalence of BPD and its association with socio-demographic factors (gender, age, and educational institution). All the participants were 18 to 25 years old and students of private universities. According to the results of this study BPD was prevalent in majority of the participants (above 50\%). There was a statistically significant difference $(<0.05)$ in the prevalence of BPD among the students of selected universities.

\section{Borderline Personality Disorder and Educational Intuitions}


One of the significant results of this study was, BPD and its prevalence among the students (young adults). The three private Universities were selected according to their hierarchical position from the general category of HEC. The results showed significant differences (P $<0.05$ ), the university which was higher in rank was reported with more cases of BPD as compared to other universities. Therefore, according to the generalized results obtained with application of BPI-cut 20, the primary symptoms were obvious among the students. These results are supported by the studies indicating the common occurrence of BPD among college and university students achieving higher education (Francey et al., 2017; Meaney et al., 2016a, 2016b). The results of the current study were further highly supported by Yen et al., who proposed that BPD was common in the population of students studying in higher education (Yen et al., 2015).

The most stressed, anxious, and depressed students belong to upper class. (Leichsenring, Leibing, Kruse, New, \& Leweke, 2011) (Taravati \& Kaklar, 2013b) (Beiter et al., 2015). Through the results and literature of the previous researches, it can be proposed that environment (setting, circumstances and location) has an important role to play in the prevalence of psychological disorder like BPD.

Table 3. Logistic Regression model between BPD and Institution.

\begin{tabular}{lccccc}
\hline \multirow{2}{*}{ Institution } & $\beta$ & S.E. & Wald $\chi 2$ & p-value & OR \\
\cline { 2 - 5 } I & & & 22.737 & .000 & \\
II & .349 & .191 & 3.323 & .068 & 1.417 \\
Constant & .944 & .201 & 22.186 & .000 & 2.572 \\
\hline
\end{tabular}

Note: Only the type of university can help in predicting the BPD status with $62 \%$ overall accuracy.

\section{Borderline Personality Disorder and Gender differences}

Another important analysis of this study was between BPD and gender. Association between gender (male and female) and prevalence of BPD was assessed through chi-square. The results obtained through this study have shown non-significant gender differences ( $p>0.05)$. These results were concluded by the application of BPIcut 20 , that generally assess the primary factors of BPD. The results of this present study are supported by the consequences of the latest studies cited in the literature (Kaess et al., 2014; Johnson et al., 2003; Zlotnick et al., 2003; Zlotnick et al., 2002). While contrary evidence was also been specified in the literature suggesting that the prevalence of BPD differs in males and females (Benson et al., 2017; Zanarini et al., 2011). Thus, it is suggested that more surveys and in-depth studies are required to be conducted to further analyze the gender differences in prevalence of BPD in detail.

\section{Borderline Personality Disorder and Age}

One more result of the current study was among age of the participants and prevalence of BPD. All the participants were young adults, of ages between 18 to 25 years. The results of this study suggested that BPD was more common in young adults who were between 18-21 years of age. The results are supported by the literature based on previously conducted researches that highlighted the importance of age and prevalence of BPD (Chanen, 2015; Newton-Howes, Horwood, et al., 2015; Newton-Howes, Clark, et al., 2015). Meanwhile, more latest research evidence was reported in literature who proposed that characteristics of BPD are obvious till adulthood (Gunderson et al., 2018; Thornton, 2018). It is expected that the reason of prevalence of BPD in particular age group, could be environmental burden, social, psychological pressure or genetical reasons.

\section{CONCLUSION AND RECOMMENDATIONS}

Through the results of the study, it is revealed that BPD was prevalent $(62 \%)$ in university students that were young adults. The university that reportedly considered better in regional position, in the list of private sector universities, was found more at risk of BPD. It is concluded that environment, circumstances, ranking and location of the university can be a cause of high prevalence of BPD among students. It is further concluded that social and emotional burden, educational competition among peers and siblings can also because of rising number of personality disorders, and its prevalence among university students. Further in-depth surveys to assess BPD, to find out the root-causes for the 
higher frequency of BPD among university students should be conducted. Counselling services to regularly evaluate and assess the mental well-being of the students, in the universities should be initiated.

\section{REFERENCES}

Beiter, R., R. Nash, M. McCrady, D. Rhoades, M. Linscomb, M. Clarahan and S. Sammut. 2015. The prevalence and correlates of depression, anxiety, and stress in a sample of college students. Journal of Affective Disorders, 173: 90-96.

Benson, K. T., M. B. Donnellan and L. C. Morey. 2017. Gender-related differential item functioning in DSM-IV/DSM-5-III (alternative model) diagnostic criteria for borderline personality disorder. Personality Disorders: Theory, Research, and Treatment, 8: 87-93.

Chanen, A. M. 2015. Borderline Personality Disorder in Young People: Are We There Yet? Journal of Clinical Psychology, 71: 778-91.

Fonseca-Pedrero, E., M. Paino, S. Lemos-Giráldez, S. Sierra-Baigrie, M. P. G.-P. González, J. Bobes and J. Muňiz. 2011. Borderline Personality Traits in Nonclinical Young Adults. Journal of Personality Disorders, 25: 542-56.

Francey, S. M., M. Jovev, C. Phassouliotis, S. M. Cotton and A. M. Chanen. 2017. Does co-occurring borderline personality disorder influence acute phase treatment for first-episode psychosis? Early Intervention in Psychiatry, 12: 1166-72.

Gunderson, J. G., S. C. Herpertz, A. E. Skodol, S. Torgersen and M. C. Zanarini. 2018. Borderline personality disorder. Nature Reviews Disease Primers, 4.

Johnson, D. M., M. T. Shea, S. Yen, C. L. Battle, C. Zlotnick, C. A. Sanislow, C. M. Grilo, A. E. Skodol, D. S. Bender, T. H. McGlashan, J. G. Gunderson and M. C. Zanarini. 2003. Gender differences in borderline personality disorder: findings from the collaborative longitudinal personality disorders study. Comprehensive Psychiatry, 44: 284-92.

Kaess, M., R. Brunner and A. Chanen. 2014. Borderline Personality Disorder in Adolescence. Pediatrics, 134: 782-93.

Leichsenring, F., E. Leibing, J. Kruse, A. S. New and F. Leweke. 2011. Borderline personality disorder. The Lancet, 377: 74-84.
Meaney, R., P. Hasking and A. Reupert. 2016a. Borderline Personality Disorder Symptoms in College Students: The Complex Interplay between Alexithymia, Emotional Dysregulation and Rumination. PloS one, 11: e0157294-e94.

Meaney, R. P. Hasking, A. Reupert. 2016b. Prevalence of Borderline Personality Disorder in University Samples: Systematic Review, Meta-Analysis and Meta-Regression. PloS one, 11: e0155439-e39.

Moran, P., H. Romaniuk, C. Coffey, A. Chanen, L. Degenhardt, R. Borschmann and G. C. Patton. 2016. The influence of personality disorder on the future mental health and social adjustment of young adults: a population-based, longitudinal cohort study. The Lancet Psychiatry, 3: 636-45.

Newton-Howes, G., L. A. Clark and A. Chanen. 2015. Personality disorder across the life course. The Lancet, 385: 727-34.

Newton-Howes, G., J. Horwood and R. Mulder. 2015. Personality characteristics in childhood and outcomes in adulthood: Findings from a 30 year longitudinal study. Australian \& New Zealand Journal of Psychiatry, 49: 377-86.

Paris, J. 2018. Clinical features of borderline personality disorder. Handbook of personality disorders: Theory, research, and treatment, 2: 419.

Shaikh, U., I. Qamar, F. Jafry, M. Hassan, S. Shagufta, Y. I. Odhejo and S. Ahmed. 2017. Patients with Borderline Personality Disorder in Emergency Departments. Frontiers in psychiatry, 8: 136-36.

Sharp, C. and P. Fonagy. 2015. Practitioner Review: Borderline personality disorder in adolescence recent conceptualization, intervention, and implications for clinical practice. Journal of Child Psychology and Psychiatry, 56: 1266-88.

Taravati, S. and A. E. Kaklar. 2013. Borderline personality disorder (BPD): An overview European Journal of Experimental Biology, 3: 326-30.

Thornton, S. 2018. Supporting students with borderline personality disorder. British Journal of School Nursing, 13: 86-88.

Tomko, R. L., T. J. Trull, P. K. Wood and K. J. Sher. 2014. Characteristics of borderline personality disorder in a community sample: comorbidity, treatment utilization, and general functioning. Journal of personality disorders, 28: 734-50. 
Zanarini, M. C., J. Horwood, D. Wolke, A. Waylen, G. Fitzmaurice and B. F. Grant. 2011. Prevalence of DSM-IV borderline personality disorder in two community samples: 6,330 English 11-year-olds and 34,653 American adults. Journal of personality disorders, 25: 607-19.

Zlotnick, C., D. M. Johnson, S. Yen, C. L. Battle, C. A. Sanislow, A. E. Skodol, C. M. Grilo, T. H. McGlashan, J. G. Gunderson, D. S. Bender, M. C. Zanarini and M. Tracie Shea. 2003. Clinical
Features and Impairment in Women with Borderline Personality Disorder (BPD) with Posttraumatic Stress Disorder (PTSD), BPD Without PTSD, and Other Personality Disorders with PTSD. Journal of Nervous \& Mental Disease, 191: 706-13.

Zlotnick, C., L. Rothschild and M. Zimmerman. 2002. The Role of Gender in the Clinical Presentation of Patients with Borderline Personality Disorder. Journal of Personality Disorders, 16: 277-82. 